\title{
Does Acetaminophen Interfere in the Antibiotic Treatment of Acute Otitis Media Caused by a Penicillin-Resistant Pneumococcus Strain? A Gerbil Model
}

\author{
CARMEN PONTE, ARACELI PARRA, CARLOS CENJOR, MARTA GARCÍA-OLMOS, \\ MARÍA JOSÉ GIMÉNEZ, LORENZO AGUILAR, ANTONIO CARCAS, AND FRANCISCO SORIANO \\ Departments of Medical Microbiology [C.P., A.P., M.G.-O., F.S.] and Otolaryngology [C.C.], Fundación \\ Jiménez Díaz, 28040 Madrid, Spain; Medical Department [M.J.G., L.A], GlaxoSmithKline, Tres Cantos, \\ 28040 Madrid, Spain; and Clinical Pharmacology [A.C.], Universidad Autónoma, 28040 Madrid, Spain
}

\begin{abstract}
The possible interference of acetaminophen, combined with antibiotics, in the treatment of acute otitis media (AOM) caused by a penicillin-resistant (minimal inhibitory concentration [MIC], $2 \mu \mathrm{g} / \mathrm{mL}$ ), amoxicillin/clavulanic acid- and erythromycin-sensitive pneumococcus was evaluated in a gerbil model. Animals were challenged with $5 \times 10^{6}$ bacteria in each ear through transbullar instillation. Acetaminophen was administered s.c. at $50 \mathrm{mg} / \mathrm{kg} 30 \mathrm{~min}$ before each antibiotic dose. Amoxicillin/clavulanic acid and erythromycin $(2.5$ and $10 \mathrm{mg} /$ $\mathrm{kg}$ ) were administered s.c. at 2, 10, and $18 \mathrm{~h}$ after inoculation. Samples were obtained from the middle ear (ME) on day 2 after inoculation for bacterial count. The overall results showed no difference between animals that received acetaminophen, with or without antibiotics, and those that did not receive acetaminophen. The antibiotic concentrations in the ME were practically identical in both groups of animals, so acetaminophen did not interfere with the pharmacokinetics of antibiotics in the ME. However, both antibiotics significantly reduced the number of culture-positive and the bacterial concentration in ME samples when compared with antibiotic-untreated animals. Both antibiotics, whether combined with acetaminophen or not, lowered the number of $\mathrm{AOM}$ to $<25 \%$, but $>75 \%$ of animals presented otitis media with effusion, and no differences were shown between groups. A high rate of bacterial eradication from the ME corre-
\end{abstract}

\section{ABSTRACT}

lated with antibiotic serum concentrations being over the MIC of the infecting organism for only $>15 \%$ of the dose interval and with an ME concentration exceeding the MIC by a factor of 1.7. In this experimental model, acetaminophen had neither a synergistic nor an antagonistic effect on the antibiotics tested. (Pediatr Res 54: 913-918, 2003)

Abbreviations
AOM, acute otitis media
BHIE, brain-heart infusion broth enriched with $5 \%$ horse
serum
C $_{\mathbf{1 5} \text { min, concentration at } 15 \text { min after antibiotic administration }}$
CFU, colony-forming units
MBC, minimal bactericidal concentration
ME, middle ear
MEF, middle ear fluid without washing
MEWF, middle ear washing fluid
MIC, minimal inhibitory concentration
MIC,
tested minimal concentration inhibiting $50 \%$ of the strains
MIC
tested minimal concentration inhibiting $90 \%$ of the strains
OME, otitis media with effusion

Acute otitis media (AOM) is one of the most frequently diagnosed infectious diseases of childhood, and the number of office visits for this pathology is increasing in many countries

Received September 10, 2002; accepted April 26, 2003.

Correspondence: Francisco Soriano, M.D., Ph.D., Department of Medical Microbiology, Fundación Jiménez Díaz, Avenida de Reyes Católicos 2, 28040 Madrid, Spain; email: fsoriano@fjd.es

This work was supported by a grant from Fondo de Investigaciones Sanitarias (FIS 99/111) and SmithKline Beecham S.A., Madrid, Spain. A.P. and M.G.-O. were aided by scholarships from the Fundación Conchita Rábago, Madrid, Spain.

DOI: 10.1203/01.PDR.0000090931.94785.DA
(1). One of the most common approaches to treating AOM in children is to administer an antibiotic to eradicate the pathogen, as well as an anti-inflammatory or analgesic drug such as acetaminophen $(2,3)$. Anti-inflammatory activity is mainly exerted through the inhibition of COX-1 and COX-2 isoenzymes that catalyze the rate-limiting step of prostaglandin synthesis (4). Recent data suggest that the little antiinflammatory activity of acetaminophen is due to its activity against COX-3 (that shows $<20 \%$ activity of COX-1 and COX -2 and is present at approximately $25 \%$ of the level of COX-1) (4). However, other agents to which COX-1, COX-2, 
and COX-3 are sensitive as ibuprofen (4), given at low doses for antipyresis, have shown to be proinflammatory (increasing neutrophil influx and cytokine levels) to a level that may have adverse clinical translations in Streptococcus pneumoniae infections (5).

The organisms most frequently involved in $\mathrm{AOM}$ are $S$. pneumoniae, Haemophilus influenzae, and Moraxella catarrhalis; therefore, antibiotics active in vitro against these bacteria are recommended (6). Amoxicillin/clavulanic acid is active against all three organisms and is one of the most frequently prescribed antimicrobial drugs in Spain (7). In countries where macrolide-resistant pneumococci are not prevalent, erythromycin or the new macrolides are also recommended $(6,8)$. Although most antibiotic treatments usually resolve the AOM, up to $70 \%$ of children develop otitis media with effusion (OME) $(9,10)$. The reason for this complication is not known, but some antibiotics may, by inducing a rapid bacterial lysis, contribute to an inflammatory response that could be responsible for the discharge (11).

The aim of this work was, first, to determine the possible interference of acetaminophen, combined with antibiotics, in the clinical and bacteriologic efficacy in AOM, in the antibiotic pharmacokinetic parameters, and in the development of OME. The second objective of this study was to find out whether antibiotics with different mechanisms of action and immunomodulatory properties (a $\beta$-lactam and a macrolide) induce, after clearing the pathogen, different rates of OME.

\section{METHODS}

Bacteria. A strain of S. pneumoniae serotype $23 \mathrm{~F}$ (minimal inhibitory concentration [MIC] for benzylpenicillin $=2 \mu \mathrm{g} /$ $\mathrm{mL}$ ) isolated from a bacteremic patient was used.

Pharmacologic compounds. Propacetamol chlorohydrate (Pro-efferalgan), a pro-drug of acetaminophen, was purchased from Upsa Laboratories (Agent-Lot et Garonne, France). Amoxicillin trihydrate, lithium clavulanate (SmithKline Beecham Pharmaceuticals, Worthing, England), and erythromycin (Sigma Chemical Co., St. Louis, MO, U.S.A.) were used for in vitro studies. For in vivo (therapeutic) use, the contents of commercial vials [Augmentin: amoxicillin/clavulanic acid, 5/1 (SmithKline Beecham S.A., Toledo, Spain) and Pantomicina: erythromycin lactobionate (Abbott Laboratories, S.A., Madrid, Spain)] were reconstituted in nonpyrogenic sterile distilled water to the desired concentrations.

In vitro studies. MICs and minimal bactericidal concentrations (MBCs) were determined by a microdilution broth method following National Committee for Clinical Laboratory Standards procedures $(12,13)$. The median of three separate determinations was used as the MIC and MBC values of each antibiotic.

Animals. Eight- to 9-wk-old adult female Mongolian gerbils (Meriones unguiculatus) that weighed $49 \pm 5 \mathrm{~g}$ each were purchased from the Center d'Élevage R. Janvier (Le Genest, St. Isle, France). They were given free access to food and water and were housed in a protected unit with a slight negative pressure and with a 12-h light and 12-h dark cycle. For invasive procedures, animals were anesthetized with $50 \mathrm{mg} / \mathrm{kg}$ body wt ketamine (Ketolar; Parke-Davis, Barcelona, Spain) and $13 \mathrm{mg} / \mathrm{kg}$ of xylazine (Rompun; Bayer, Leverkusen, Germany) by intramuscular route.

The study was performed in accordance with prevailing regulations regarding the care and use of laboratory animals in the European Community (14) and approved by the Review Board for Animal Experimentation of Fundación Jiménez Díaz.

Experimental otitis. On the day of experimentation, $S$. pneumoniae was incubated for $4 \mathrm{~h}$ at $35^{\circ} \mathrm{C}$ in a $5 \% \mathrm{CO}_{2}$ atmosphere in brain-heart infusion broth (Oxoid, Ltd, Basingstoke, Hampshire, England) enriched with $5 \%$ horse serum (BHIE; bioMérieux, Marcy-L'Étoile, France). Animals were inoculated bilaterally, as previously reported (15), with $\sim 5 \times$ $10^{6} \mathrm{CFU}$ of $S$. pneumoniae per $20 \mu \mathrm{L}$, which was introduced directly in the middle ear (ME) bulla. The number of viable bacteria in the different inocula was determined by colony counting. The tympanic membrane was left intact and swelled without rupture during the inoculation. A normal tympanic aspect and correct inoculation were verified by an otolaryngologist by direct otomicroscopy using an operating microscope. AOM was defined as otorrhea through a perforation in the tympanic membrane and/or inflammatory signs with changes in the membrane's normal yellowish-pink appearance to a gray, dark brownish-yellow or whitish opaque area, with a very rough surface texture. OME was defined as no inflammatory signs of tympanic membrane with air fluid levels or ME fluid with or without signs of negative ME pressure. Three animals (six ears) were inoculated with $20 \mu \mathrm{L}$ of BHIE/ear to find out the possible role of broth as inductor of otitis media. For exploring the presence of bacteremia in infected animals, blood cultures were performed in four animals $20 \mathrm{~h}$ after bacterial inoculation.

Treatment regimen and efficacy studies. Each antibiotic was tested at two doses $\left(2.5\right.$ and $\left.10 \mathrm{mg} \cdot \mathrm{kg}^{-1} \cdot \mathrm{dose}^{-1}\right)$ and was administered s.c. in $500 \mu \mathrm{L}$ at 2,10 , and $18 \mathrm{~h}$ after inoculation. Antibiotics were administered alone or combined with $50 \mathrm{mg} / \mathrm{kg}$ of propacetamol administered s.c. $30 \mathrm{~min}$ before each antibiotic dose, in experiments carried out in parallel. Two groups of antibiotic-untreated animals received apyrogenated sterile distilled water instead of antibiotic, one of which also received propacetamol. Groups of 12 animals per treatment and control groups were included. Treated and control animals were studied longitudinally for otorrhea, weight, and behavior. The otoscopic aspect and ME samples were obtained from both ears on day 2 after inoculation by washing the ME fossa with $20 \mu \mathrm{L}$ of saline injected and withdrawn via the epitympanic membrane with a $0.33-\mathrm{mm}$ needle to determine bacterial counts in ME washing fluid (MEWF). Shortly after sampling, aliquots of serial 10-fold dilutions in saline were plated onto sheep blood agar and incubated for $24 \mathrm{~h}$ at $35^{\circ} \mathrm{C}$ in a $5 \% \mathrm{CO}_{2}$ atmosphere. Bacterial counts are expressed as $\log _{10}$ ' colony-forming units $(\mathrm{CFU}) / 20 \mu \mathrm{L}$; the lowest detectable bacterial count was $4 \mathrm{CFU} / 20 \mu \mathrm{L}\left(0.60 \log _{10} \mathrm{CFU} / 20 \mu \mathrm{L}\right)$. For evaluating the presence of polymorphonuclear leukocytes, 3 $\mu \mathrm{L}$ of MEWF was extended over a $6-\mathrm{cm}^{2}$ slide surface to be Gram stained and observed under a high-power $(\times 1000)$ mi- 
croscope. The number of cells in 10 fields was calculated and expressed as mean (SD) per field.

Pharmacokinetic studies. Serum levels of acetaminophen were determined in healthy animals 15 and $30 \mathrm{~min}$ after s.c. administration of $50 \mathrm{mg} / \mathrm{kg}$ of propacetamol, by Fluorescence Polarization Immunoassay in an Axsym autoanalyser (Abbott Científica, Madrid, Spain). Groups of six animals per sample time were killed with $\mathrm{CO}_{2}$ and were exsanguinated by intracardiac puncture. The limit of detection was $1 \mu \mathrm{g} / \mathrm{mL}$.

Serum levels of amoxicillin, clavulanic acid, and erythromycin were determined in healthy animals after a single s.c. injection of the same doses used for the treatment. Groups of six animals per dose and blood sample time $(15,30,60$, and 120 min after drug administration) were killed as described for acetaminophen.

Antibiotic concentrations in ME fluid without washing (MEF) were also determined in groups of 10 animals bilaterally inoculated under the same conditions as previously indicated in the experimental otitis model. Single doses of 2.5 $\mathrm{mg} / \mathrm{kg}$ of either antibiotic, alone and combined with propacetamol, were administered s.c. $46 \mathrm{~h}$ after bacterial inoculation. MEF samples were obtained 90 min later, via the epitympanic membrane, with a $0.33-\mathrm{mm}$ needle. Aliquots of MEF samples having $>2 \mu \mathrm{L}$ of exudate were pooled and frozen at $-70^{\circ} \mathrm{C}$ until determination of antibiotic levels. This procedure permits collection of MEF samples at a time when effusion is consistently abundant with high bacterial density and without otorrhea.

Antibiotic concentrations were determined by microbiological assay with Micrococcus luteus ATCC 9341 and Klebsiella pneumoniae NCTC 11228. Standard curves for determination of antibiotic concentrations were obtained from standard solutions prepared in pooled gerbils' sera for serum levels and in $0.1 \mathrm{~mol} / \mathrm{L}$ phosphate buffer ( $\mathrm{pH}$ 6.0) for MEF. The variability of the assay for individual samples was $<10 \%$. Antibiotic concentration-time curves for each antimicrobial were analyzed by a noncompartmental approach using the Win-Nonlin program (Pharsight, Mountainview, CA, U.S.A.). Half-life was calculated by the expression $t_{1 / 2}=(\ln 2) / \mathrm{Kel}$, where $\mathrm{Kel}$ is the apparent elimination rate constant calculated by least square regression from at least three time-point values. Time over MIC was calculated graphically from the semilogarithmic representation of the concentration-time curve and the regression line representing the Kel. The relationship between the maximum antibiotic serum concentration obtained [concentration at 15 min after antibiotic administration $\left.\left(\mathrm{C}_{15} \mathrm{~min}\right)\right]$ and the MIC of the infecting microorganism [serum inhibitory quotient $\left(\mathrm{C}_{15}\right.$ $\min / \mathrm{MIC})]$ and the relationship between the MEF antibiotic concentration after 90 min of drug administration and the MIC of the infecting microorganism (MEF inhibitory quotient: MEF level/MIC) were calculated.

Statistical analysis. The number of ears with a positive count divided by the total number of ears was calculated to give the percentage of positive ears in each group of animals. For detecting differences in eradication rates in each group, the Fisher's exact test was used, with Bonferroni correction for multiple comparisons. Otorrhea at day 1 was analyzed using the $\chi^{2}$ test and the Fisher's exact test for paired comparisons with the Bonferroni correction for multiple comparisons. Bac- terial counts were expressed in untreated and treated animals as arithmetic means in $\log _{10} \mathrm{CFU}$ per $20 \mu \mathrm{L}$ of MEWF, culturenegative samples being included in the calculation of means assuming a value at the detection limit. ANCOVA was used to compare the reduction of $\log _{10} \mathrm{CFU}$ and loss of body weight at day 2 in each group controlled for the $\log _{10} \mathrm{CFU}$ or weight basal values and for the differences by groups. ANOVA was used to compare MEWF volume and polymorphonuclear leukocyte counts. When the ANCOVA or ANOVA $p$ value was significant $(p<0.05)$, contrast between groups was made by use of the Tukey-Kramer test to adjust the type I experimentwise error.

\section{RESULTS}

In vitro studies. The $\mathrm{MIC} / \mathrm{MBC}$ of the antibiotics (referred to as amoxicillin in the case of amoxicillin/clavulanic acid) for the pneumococcal strain used was $1 / 1$ and $0.12 / 0.12 \mu \mathrm{g} / \mathrm{mL}$ for amoxicillin and erythromycin, respectively.

Experimental otitis. Animals inoculated with BHIE showed neither clinical nor otoscopic signs of disease and at day 2; the MEWF was culture-negative. After S. pneumoniae inoculation (6.54 $\pm 0.27 \log _{10}$ CFU), bilateral AOM was obtained in $98 \%$ of all ears from animals that did not receive antibiotics at day 2 , with $100 \%$ of culture-positive MEWF samples. Most MEWF specimens contained between 7.5 and 10.8 polymorphonuclear cells per field with intra- and extracellular organisms. Animals showed lethargy, with an important weight loss and $66.6 \%$ of otorrheic ears. There were no differences between animals that received acetaminophen and those that did not receive it. Blood cultures were positive for the organisms in three of the four inoculated animals from which blood samples were taken.

Therapeutic efficacy in experimental otitis. All animals that received antibiotics at any dose were active and showed normal behavior. Table 1 presents the comparative therapeutic results for controls and antibiotic-treated animals. Both antibiotics, at any dose, with or without acetaminophen, significantly reduced the number of culture-positive MEWF specimens and the number of organisms when compared with antibiotic-untreated animals $(p<0.001)$. No statistical differences were found between antibiotic-treated groups (combined or not with acetaminophen).

Table 2 presents the data from the otoscopic examination, otorrhea, volume of MEWF recovered, presence of polymorphonuclear cells, and weight loss. All animals that received antibiotics had low percentages of AOM, and few had positive cultures. Most antibiotic-treated animals developed posttreatment OME, and no differences were detected between doses or antibiotics (with or without acetaminophen). All antibiotictreated animals showed lower percentages of otorrhea compared with untreated controls, although differences were significant only for both doses of amoxicillin/clavulanic acid $(p<$ 0.05). In addition, animals treated with the high dose of amoxicillin/clavulanic acid had significantly less otorrhea than animals treated with the low dose of erythromycin $(p<0.001)$. The presence of otorrhea correlated directly with AOM, with no differences being shown between animals that received 
Table 1. Outcome on day 2 of AOM caused by penicillin-resistant S. pneumoniae treated with acetaminophen, amoxicillin/clavulanic acid, and erythromycin

\begin{tabular}{|c|c|c|c|c|c|c|}
\hline \multirow[b]{2}{*}{ Group } & \multirow[b]{2}{*}{ No. of animals } & \multicolumn{3}{|c|}{$\begin{array}{l}\text { No. }(\%) \text { of animals with } \\
\text { culture-positive ME samples }\end{array}$} & \multirow{2}{*}{$\begin{array}{l}\text { No. }(\%) \text { of } \mathrm{ME} \\
\text { culture-positive } \\
\text { samples }\end{array}$} & \multirow{2}{*}{$\begin{array}{c}\text { Bacterial counts } \\
\log _{10} \mathrm{CFU}^{*} \\
{[\text { mean }(\mathrm{SD})]}\end{array}$} \\
\hline & & Bilateral & Unilateral & Total & & \\
\hline Untreated controls & 12 & $12(100)$ & $0(0.0)$ & $12(100)$ & $24(100)$ & $3.23(1.01)$ \\
\hline $\mathrm{ACE}, 50 \mathrm{mg} / \mathrm{kg}$ & 12 & $12(100)$ & $0(0.0)$ & $12(100)$ & $24(100)$ & $3.14(0.93)$ \\
\hline $\mathrm{A} / \mathrm{C}, 2.5 \mathrm{mg} / \mathrm{kg} \dagger$ & 12 & $0(0.0)$ & $0(0.0)$ & $0(0.0)$ & $0(0.0) \ddagger$ & $<0.60 \ddagger$ \\
\hline $\mathrm{A} / \mathrm{C}, 2.5 \mathrm{mg} / \mathrm{kg}+\mathrm{ACE}, 50 \mathrm{mg} / \mathrm{kg}$ & 12 & $0(0.0)$ & $1(8.3)$ & $1(8.3)$ & $1(4.2) \div$ & $0.64(0.25) \div$ \\
\hline $\mathrm{A} / \mathrm{C}, 10 \mathrm{mg} / \mathrm{kg}$ & 12 & $0(0.0)$ & $0(0.0)$ & $0(0.0)$ & $0(0.0) \div$ & $<0.60 \ddagger$ \\
\hline $\mathrm{A} / \mathrm{C}, 10 \mathrm{mg} / \mathrm{kg}+\mathrm{ACE}, 50 \mathrm{mg} / \mathrm{kg}$ & 12 & $0(0.0)$ & $0(0.0)$ & $0(0.0)$ & $0(0.0) \div$ & $<0.60 \ddagger$ \\
\hline $\mathrm{ERY}, 2.5 \mathrm{mg} / \mathrm{kg}$ & 12 & $0(0.0)$ & $1(8.3)$ & $1(8.3)$ & $1(4.2) \ddagger$ & $0.66(0.36) \ddagger$ \\
\hline $\mathrm{ERY}, 2.5 \mathrm{mg} / \mathrm{kg}+\mathrm{ACE}, 50 \mathrm{mg} / \mathrm{kg}$ & 12 & $1(8.3)$ & $2(16.7)$ & $3(25.0)$ & $4(16.7) \div$ & $0.82(0.64) \dagger$ \\
\hline $\mathrm{ERY}, 10 \mathrm{mg} / \mathrm{kg}$ & 12 & $0(0.0)$ & $0(0.0)$ & $0(0.0)$ & $0(0.0) \ddagger$ & $<0.60 \ddagger$ \\
\hline $\mathrm{ERY}, 10 \mathrm{mg} / \mathrm{kg}+\mathrm{ACE}, 50 \mathrm{mg} / \mathrm{kg}$ & 12 & $0(0.0)$ & $0(0.0)$ & $0(0.0)$ & $0(0.0) \ddagger$ & $<0.60 \%$ \\
\hline
\end{tabular}

ACE, acetaminophen; A/C, amoxicillin/clavulanic acid; ERY, erythromycin.

* Values are the mean $\log _{10} \mathrm{CFU}$ in $20 \mu \mathrm{L}$ of washing fluid. Data for culture-negative samples were included in the calculation of means by assuming a value at the detection limit $\left(0.60 \log _{10} \mathrm{CFU}\right)$.

$\dagger$ Referred as amoxicillin.

$\ddagger$ Differences between values for treated with antibiotics $v$ s those for antibiotic-untreated animals were statistically significant $(p<0.0001)$.

Table 2. Relationship between otoscopic examination, presence of otorrhea, volume ( $\mu$ L), and polymorphonuclear leukocytes of middle ear washing fluid recovered, and variation in body weight in an experimental otitis media caused by S. pneumoniae*

\begin{tabular}{|c|c|c|c|c|c|c|}
\hline Group & \multicolumn{2}{|c|}{ Otoscopic examination (\%) } & $\begin{array}{c}\text { Otorrhea } \\
(\%)\end{array}$ & $\begin{array}{c}\text { Volume } \\
{[\text { mean }(\mathrm{SD})]}\end{array}$ & $\begin{array}{c}\text { PMN } \\
{[\text { mean (SD)] }}\end{array}$ & $\begin{array}{c}\% \text { Body weight loss } \\
{[\text { mean (SD) }]}\end{array}$ \\
\hline Untreated controls & $23(95.8)$ & $1(4.2)$ & 62.5 & $21.8(6.9)$ & $7.5(10.7)$ & $-11.6(2.1)$ \\
\hline $\mathrm{A} / \mathrm{C}, 2.5 \mathrm{mg} / \mathrm{kg} \dagger$ & $0(0.0)$ & $24(100)$ & $12.5 \ddagger$ & $21.1(8.9)$ & $1.8(2.4) !$ & $-2.5(2.6) \ddagger$ \\
\hline $\mathrm{A} / \mathrm{C}, 2.5 \mathrm{mg} / \mathrm{kg}+\mathrm{ACE}, 50 \mathrm{mg} / \mathrm{kg}$ & $4(16.7)$ & $20(83.3)$ & $12.5 \div$ & $28.8(13.4)$ & $1.6(1.7) \div$ & $-2.8(2.9) \dagger$ \\
\hline $\mathrm{A} / \mathrm{C}, 10 \mathrm{mg} / \mathrm{kg}$ & $1(4.2)$ & $23(95.8)$ & $0.0 \ddagger \S$ & $25.1(8.7)$ & $2.8(1.5) \ddagger$ & $-4.6(2.2) \dagger$ \\
\hline ERY, $2.5 \mathrm{mg} / \mathrm{kg}+\mathrm{ACE}, 50 \mathrm{mg} / \mathrm{kg}$ & $4(16.7)$ & $20(83.3)$ & 29.2 & $23.0(5.9)$ & $1.6(2.6) \ddagger$ & $-3.7(3.3) \div$ \\
\hline $\mathrm{ERY}, 10 \mathrm{mg} / \mathrm{kg}$ & $0(0.0)$ & $24(100)$ & 25.0 & $21.2(7.7)$ & $1.9(1.6) \div$ & $-3.7(2.4) \ddagger$ \\
\hline ERY, $10 \mathrm{mg} / \mathrm{kg}+\mathrm{ACE}, 50 \mathrm{mg} / \mathrm{kg}$ & $2(8.3)$ & $22(91.7)$ & 33.3 & $23.5(8.9)$ & $1.9(2.4) \div$ & $-3.4(3.1) \div$ \\
\hline
\end{tabular}

PMN, poly morphonuclear leukocytes.

* Data referred at day 2 except otorrhea (day 1$)$.

$\dagger$ Referred as amoxicillin.

$\ddagger$ Differences between values for treated with antibiotics $v s$. those for antibiotic-untreated animals were statistically significant $(p<0.01$ for otorrhea and $p<$ 0.05 for PMN and weight loss).

$\S$ Statistically significant differences versus ERY $2.5 \mathrm{mg} / \mathrm{kg}$.

acetaminophen and those that did not receive it. As far as the volume of MEWF is concerned, there were no differences between groups. All antibiotic-treated animals had lower amounts of polymorphonuclear cells in the MEWF compared with controls $(p<0.05)$, with no differences between groups. With regard to loss of body weight (as recorded on day 2), all antibiotic-treated animals lost less weight than the antibioticuntreated controls $(p<0.001)$ without differences being shown between groups.

Pharmacokinetic and pharmacodynamic data. Serum levels of acetaminophen after administration of $50 \mathrm{mg} / \mathrm{kg}$ were $39.6 \pm 8.2 \mu \mathrm{g} / \mathrm{mL}$ and $24.7 \pm 4.4 \mu \mathrm{g} / \mathrm{mL}$ at 15 and $30 \mathrm{~min}$, respectively. Table 3 presents the serum and MEF (with or without acetaminophen) pharmacokinetic data for amoxicillin/ clavulanic acid and erythromycin. Serum half-lives for amoxicillin/clavulanic acid were shorter than for erythromycin. ME antibiotic concentrations were lower for erythromycin than for amoxicillin/clavulanic acid. Nevertheless, penetration of amoxicillin/clavulanic acid (approximately 31/25\%) was lower than that of erythromycin (approximately 53\%) in relation to serum concentrations at $15 \mathrm{~min}$. The administration of acetaminophen in addition to the $2.5 \mathrm{mg} / \mathrm{kg}$ dose of either amoxicillin/clavulanic acid or erythromycin did not influence the antibiotic concentration in the ME (as compared with animals that received only antibiotic).

Table 4 presents the pharmacodynamic analysis in relation to the organism inoculated and the percentage of bacterial eradication. Serum inhibitory quotients $\left(\mathrm{C}_{15 \mathrm{~min}} / \mathrm{MIC}\right)$ were $>5$ and time above $\mathrm{MIC}>70 \mathrm{~min}$ (i.e. $15-25 \%$ of the dose interval) for both antibiotics, and these values correlated with bacterial eradication $(>83 \%)$. The MEF inhibitory quotients (antibiotic concentration in the MEF/MIC) for the lower doses of both antibiotics were higher than 1 .

\section{DISCUSSION}

For the present study, we selected a penicillin-resistant, erythromycin-sensitive pneumococcal strain serotype $23 \mathrm{~F}$, because these characteristics are representative of the strains commonly found to be responsible for AOM in children (7, 
Table 3. Pharmacokinetic data for A/C and ERY in serum and MEF in relation to S. pneumoniae susceptibility

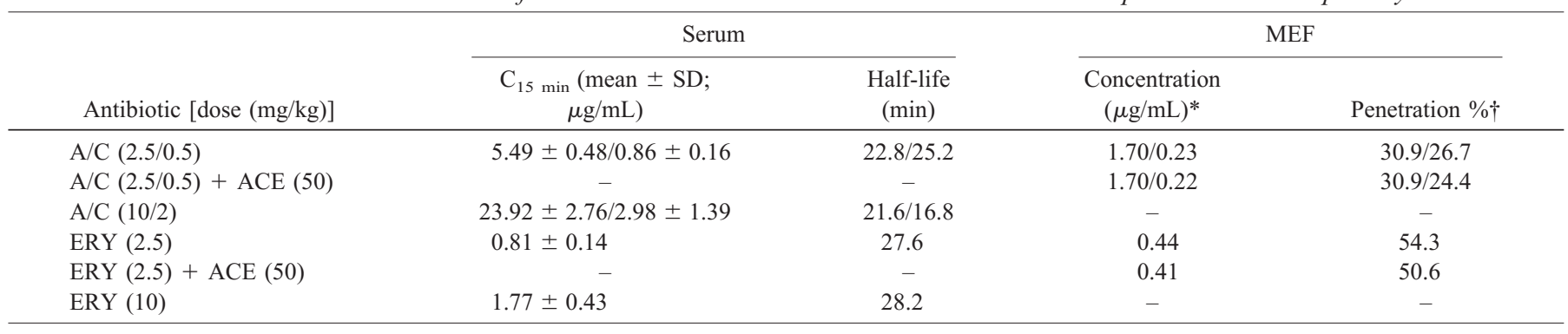

* Antibiotic concentration in MEF 90 min after drug administration.

$\dagger$ In relation to the serum concentration at $15 \mathrm{~min}$.

Table 4. Pharmacodynamic data for $A / C^{*}$ and ERY in serum and $M E F$ in relation to $S$. pneumoniae susceptibility

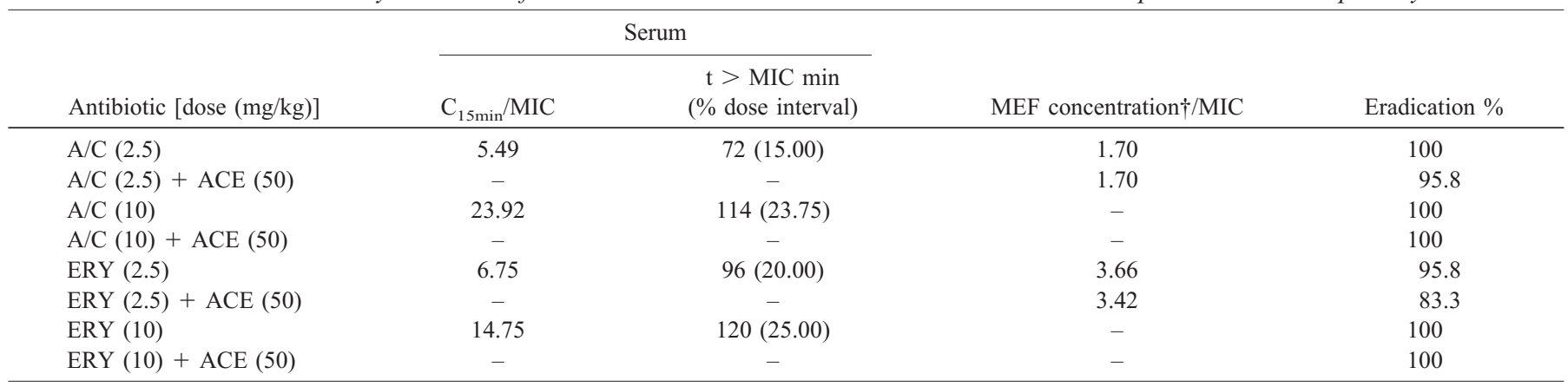

* Referred as amoxicillin

$\dagger$ Antibiotic concentration in MEF 90 min after drug administration.

16). The MIC for erythromycin represents $\mathrm{MIC}_{50}$ in Spain (17), although significantly higher erythromycin resistance prevalence is found in patients with otitis $(47 \%)$, with an $\mathrm{MIC}_{90}>64 \mu \mathrm{g} / \mathrm{mL}$ as a result of the prevalence of the $\mathrm{MLS}_{\mathrm{B}}$ constitutive phenotype (17).

Low antibiotic doses were chosen to obtain in gerbils serum levels similar to those obtained in children after standard oral doses of both antibiotics (18). For investigating whether higher doses could induce different rates of OME, a second regimen of each antibiotic was also used, so as to attain in gerbils serum concentrations similar to those attainable in children treated with high doses (18-20).

Amoxicillin/clavulanic acid and erythromycin both were efficacious, at any dose, in eradicating this penicillin-resistant, erythromycin-sensitive pneumococcus from the ME and in avoiding the occurrence of AOM as compared with controls. In addition, antibiotic-treated animals were active and had low loss of body weight as compared with controls. Such efficacy was obtained with antibiotic serum concentrations exceeding the MIC of the pathogen by $>70 \mathrm{~min}$ (i.e. from $15 \%$ to $25 \%$ of the dosing interval), a value lower than that previously suggested (21). However, these data corroborated the results obtained by our group in a previous animal model of AOM caused by penicillin-resistant pneumococci treated with low doses of amoxicillin (22). The concentrations of both amoxicillin/clavulanic acid and erythromycin in the ME, as well as the percentages of penetration, were very similar to rates reported in children with AOM (18-20). The inhibitory quotient, calculated taking into account the ME concentrations (antibiotic concentration in MEF/MIC) was $>1.6$, thus indicating that the antibiotic concentration in the infectious foci was higher than the MIC of the offending penicillin-resistant, erythromycin-sensitive pneumococcus. In this study, as has been demonstrated previously (23), the main pharmacodynamic parameter predicting antibiotic efficacy in otitis media is the MEF inhibitory quotient. Clinical and bacteriologic success was obtained when the antibiotic concentration in the MEF exceeded the MIC of the pathogen, which may, to some extent, be independent of serum levels $(23,24)$.

Most animals treated with antibiotics developed OME, regardless of whether they were treated with amoxicillin/ clavulanic acid or with erythromycin. The immunomodulatory effect of erythromycin is well known $(25,26)$, and because its mechanism of action is different from that of $\beta$ - lactam antibiotics, macrolides could induce a lower inflammatory response than $\beta$-lactams do (27-29). The hypothesis of this study was that such differences could affect the rate of OME, but it has not been corroborated in this experimental study, as had occurred in a previous study carried out using clarithromycin in the chinchilla model (30).

The administration of acetaminophen concomitantly with either amoxicillin/clavulanic acid or erythromycin did not affect the antibiotic concentration in the ME; therefore, we did not study the possible interference in serum pharmacokinetics. Some pharmacokinetic interactions between antibiotics and nonsteroidal anti-inflammatory or antipyretic drugs have been described in experimental models but very rarely in humans (31-33). Carsenti-Etesse et al. (34) reported some interference of acetaminophen in the bactericidal activity of cefixime against $S$. pneumoniae. In our experimental model, no significant differences were found in clinical, otoscopic, or bacteriologic parameters between antibiotic-untreated animals that 
received acetaminophen and those that did not receive it, and this could be related to the weak anti-inflammatory activity of the compound (35). Furthermore, there were no significant differences in antibiotic efficacy between animals that did and did not receive acetaminophen. Nevertheless, this may be a power issue because in the lower erythromycin dose group, worse rates (without significant statistical differences) are found in the presence of acetaminophen (16.7\% versus $4.2 \%)$, and the only failure obtained with the low dose of amoxicillin/ clavulanic acid received acetaminophen concomitantly. At higher doses, antimicrobial effects may be too potent to detect any possible interference. Further studies are warranted because low doses are not uncommon as a result of poor compliance or to a decreased susceptibility of the infecting organism. In addition, acetaminophen did not prevent the appearance of OME, suggesting that no clear benefit may be expected from combining antibiotics with acetaminophen. Nonetheless, because acetaminophen may alleviate ear pain and decrease body temperature (35), its use, alone or combined with an antibiotic, may be advocated.

\section{REFERENCES}

1. Schappert SM 1992 Office visit for otitis media: United States, 1975-90. Adv Data $8: 1-19$

2. Hoberman A, Paradise JL, Reynolds EA, Urkin J 1997 Efficacy of Auralgan for treating ear pain in children with acute otitis media. Arch Pediatr Adolesc Med 151:675-678

3. Little P, Gould C, Williamson I, Moore M, Warner G, Dunleavey J 2001 Pragmatic randomised controlled trial of two prescribing strategies for childhood acute otitis media. BMJ 322:336-342

4. Chandrasekharan NV, Dai H, Roos KL, Evanson NK, Tomsik J, Elton TS, Simmons DL 2002 COX-3, a cyclooxygenase-1 variant inhibited by acetaminophen and other analgesic/antipyretic drugs: cloning, structure, and expression. Proc Natl Acad Sci USA 99:13926-13931

5. Byington CL, Spencer LY, Johnson TA, Pavia AT, Allen D, Mason EO, Kaplan S, Carroll KC, Daly JA, Christenson JC, Samore MH 2002 An epidemiological investigation of a sustained high rate of pediatric parapneumonic empyema: risk factors and microbiological associations. Clin Infect Dis 34:434-440

6. Klein OG 2000 Otitis externa, otitis media, and mastoiditis. In: Mandell GL, Bennett JE, Dolin R (eds) Principles and Practice of Infectious Diseases. Churchill Livingstone, Philadelphia, pp 669-675

7. del Castillo F, Baquero-Artigao F, Garcia-Perea A 1998 Influence of recent antibiotic therapy on antimicrobial resistance of Streptococcus pneumoniae in children with acute otitis media in Spain. Pediatr Infect Dis J 17:94-97

8. Takata GS, Chan LS, Shekelle P, Morton SC, Mason W, Marcy SM 2001 Evidence assessment of management of acute otitis media: I. The role of antibiotics in treatmen of uncomplicated acute otitis media. Pediatrics 108:239-247

9. Roger G, Carles P, Pangon B, Thien HV, Polonovski JM, Begue P, Garabedian EN 1998 Management of acute otitis media caused by resistant pneumococci in infants Pediatr Infect Dis J 17:631-638

10. Teele DW, Klein JO, Rosner B 1989 Epidemiology of otitis media during the firs seven years of life in children in greater Boston: a prospective, cohort study. J Infect Dis 160:83-94

11. Kawana M, Kawana C, Giebink GS 1992 Penicillin treatment accelerates middle ea inflammation in experimental pneumococcal otitis media. Infect Immun 60:19081912

12. National Committee for Clinical Laboratory Standards 1992 Methods for Determining Bactericidal Activity of Antimicrobial Agents, Document M26-T. Villanova, PA, National Committee for Clinical Laboratory Standards

13. National Committee for Clinical Laboratory Standards 1997 Methods for Dilution Antimicrobial Susceptibility Tests for Bacteria That Grow Aerobically-Fourth
Edition: Approved Standard M7-A4. Villanova, Pa, National Committee for Clinical Laboratory Standards

14. European C 1986 Journal officiel des communautés européennes. Luxembourg, Office des publications officielles des communautés européennes

15. Cenjor C, Ponte C, Parra A, Nieto E, Garcia-Calvo G, Gimenez MJ, Aguilar L, Soriano F 1998 In vivo efficacies of amoxicillin and cefuroxime against penicillinresistant Streptococcus pneumoniae in a gerbil model of acute otitis media. Antimicrob Agents Chemother 42:1361-1364

16. Jacobs MR, Dagan R, Appelbaum PC, Burch DJ 1998 Prevalence of antimicrobialresistant pathogens in middle ear fluid: multinational study of 917 children with acute otitis media. Antimicrob Agents Chemother 42:589-595

17. Perez-Trallero E, Fernandez-Mazarrasa C, Garcia-Rey C, Bouza E, Aguilar L, Garcia-de-Lomas J, Baquero F 2001 Antimicrobial susceptibilities of 1,684 Streptococcus pneumoniae and 2,039 Streptococcus pyogenes isolates and their ecological relationships: results of a 1-year (1998-1999) multicenter surveillance study in Spain. Antimicrob Agents Chemother 45:3334-3340

18. Ginsburg CM, McCracken GH Jr, Nelson JD 1981 Pharmacology of oral antibiotics used for treatment of otitis media and tonsillopharyngitis in infants and children. Ann Otol Rhinol Laryngol Suppl 90:37-43

19. Canafax DM, Yuan Z, Chonmaitree T, Deka K, Russlie HQ, Giebink GS 1998 Amoxicillin middle ear fluid penetration and pharmacokinetics in children with acute otitis media. Pediatr Infect Dis J 17:149-156

20. Seikel K, Shelton S, McCracken GH Jr 1997 Middle ear fluid concentrations of amoxicillin after large dosages in children with acute otitis media. Pediatr Infect Dis J 16:710-711

21. Craig WA, Andes D 1996 Pharmacokinetics and pharmacodynamics of antibiotics in otitis media. Pediatr Infect Dis J 15:255-259

22. Parra A, Ponte C, Cenjor C, Garcia-Calvo G, Gimenez MJ, Aguilar L, Soriano F 2002 Optimal dose of amoxicillin in treatment of otitis media caused by a penicillinresistant pneumococcus strain in the gerbil model. Antimicrob Agents Chemother 46:859-862

23. Soriano F, Parra A, Cenjor C, Nieto E, Garcia-Calvo G, Gimenez MJ, Aguilar L, Ponte C 2000 Role of Streptococcus pneumoniae and Haemophilus influenzae in the development of acute otitis media and otitis media with effusion in a gerbil model. J Infect Dis 181:646-652

24. Ponte C, Cenjor C, Parra A, Nieto E, Garcia-Calvo G, Gimenez MJ, Aguilar L, Soriano F 1999 Antimicrobial treatment of an experimental otitis media caused by a beta-lactamase positive isolate of Haemophilus influenzae. J Antimicrob Chemother 44:85-90

25. Labro MT 1998 Anti-inflammatory activity of macrolides: a new therapeutic potential? J Antimicrob Chemother 41(suppl B):37-46

26. Schultz MJ, Speelman P, Zaat S, van Deventer SJ, van der Poll T 1998 Erythromycin inhibits tumor necrosis factor alpha and interleukin 6 production induced by heatkilled Streptococcus pneumoniae in whole blood. Antimicrob Agents Chemother 42:1605-1609

27. Cundell D, Masure HR, Tuomanen EI 1995 The molecular basis of pneumococcal infection: a hypothesis. Clin Infect Dis 21(suppl 3):S204-S211

28. Tuomanen E, Rich R, Zak O 1987 Induction of pulmonary inflammation by components of the pneumococcal cell surface. Am Rev Respir Dis 135:869-874

29. van Langevelde P, van Dissel JT, Ravensbergen E, Appelmelk BJ, Schrijver IA, Groeneveld PH 1998 Antibiotic-induced release of lipoteichoic acid and peptidoglycan from Staphylococcus aureus: quantitative measurements and biological reactivities. Antimicrob Agents Chemother 42:3073-3078

30. Alper CM, Doyle WJ, Seroky JT, Bluestone CD 1996 Efficacy of clarithromycin treatment of acute otitis media caused by infection with penicillin-susceptible, -intermediate, and -resistant Streptococcus pneumoniae in the chinchilla. Antimicrob Agents Chemother 40:1889-1892

31. Carbon C 1990 [Antibiotics and anti-inflammatory agents: drug interactions]. Pathol Biol (Paris) 38:255-260

32. Dellamonica P, Garraffo R, Etesse-Carsenti H, Bernard E, Mondain V 1993 Pharmacokinetic and bacteriological study of cefadroxil-salicylate and josamycin-salicylate drug regimens. Int J Clin Pharmacol Res 13:11-20

33. Tuomanen E, Hengstler B, Rich R, Bray MA, Zak O, Tomasz A 1987 Nonsteroidal anti-inflammatory agents in the therapy for experimental pneumococcal meningitis. J Infect Dis 155:985-990

34. Carsenti-Etesse H, Farinotti R, Durant J, Roger PM, De Salvador F, Bernard E, Rouveix B, Dellamonica P 1998 Pharmacokinetic parameters and killing rates in serum of volunteers receiving amoxicillin, cefadroxil or cefixime alone or associated with niflumic acid or paracetamol. Eur J Drug Metab Pharmocokinet 23:357-366

35. Botting RM 2000 Mechanism of action of acetaminophen: is there a cyclooxygenase 3? Clin Infect Dis 31(suppl 5):S202-S210 